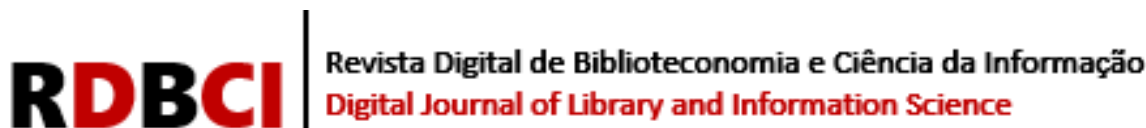

$\mathbf{I S S}_{1678-765 \mathrm{X}}$

10.20396/rdbci.v19ioo.8664905

(c) (i) BY

ARTIGO

\section{Teoria Ator-Rede (TAR) como alternativa à superação das dualidades presentes nos estudos de comportamento informacional}

\author{
Eduardo Andrade ${ }^{1}$ (ID) https://orcid.org/0000-0002-9158-5125 \\ Rodrigo Moreno Marques 2 (D) https://orcid.org/0000-0002-6320-4874 \\ ${ }^{1}$ Universidade Federal de Minas Gerais, Belo Horizonte, MG, Brasil / e-mail: prof.eduardoandrade@yahoo.com.br \\ ${ }^{2}$ Universidade Federal de Minas Gerais, Belo Horizonte, MG, Brasil / e-mail: rodrigomorenomarques@yahoo.com.br
}

\begin{abstract}
RESUMO
Introdução: No campo dos estudos de usuários da informação, a mudança do paradigma centrado no sistema para o centrado no usuário da informação trouxe aspectos individuais e cognitivos das atividades informacionais para o primeiro plano. Esse ponto de vista foi criticado por abordagens sociais emergentes por negligenciar aspectos sociais e de contexto. Esse movimento gera tensões entre investigadores que adotam posicionamentos focados na centralidade no usuário, ou no contexto ou em alguma posição intermediária entre os dois polos, o que inevitavelmente interfere nos resultados de suas pesquisas. Objetivo: $\mathrm{O}$ artigo objetiva analisar a Teoria Ator-Rede (TAR) como uma alternativa às polaridades reducionistas presentes no campo de estudos de usuários. Metodologia: A análise foi realizada por meio de revisão bibliográfica sobre estudos de usuários, comportamento informacional e TAR. Resultados: $O$ estudo revela uma abordagem diferenciada no rastreamento de atividades informacionais ao considerar que usuários da informação, sejam eles individuais ou coletivos, continuamente trocam propriedades em um mesmo plano, sem a referida polarização ou a busca por posições intermediárias. Conclusões: $O$ artigo apresenta a TAR não apenas como uma alternativa coerente, mas oportuna para a apreensão de fenômenos informacionais contemporâneos.
\end{abstract}

PALAVRAS-CHAVE

Teoria Ator-Rede (TAR). Comportamento informacional. Estudos de usuários.

\section{Actor-Network Theory (ANT) as an alternative to overcoming the dualities of the informational behavior studies}

\begin{abstract}
Introduction: In the field of information user studies, the shift from the system-centered to the user-centered information paradigm brought to the forefront individual and cognitive aspects of informational activities. This point of view was criticized by emerging social approaches for neglecting social and contextual aspects. This movement generates tensions between researchers who adopt positions focused on the centrality on the user, or on the context or some intermediate position between the two poles, which inevitably interferes with the results of their researches. Objective: The article aims to analyze the Actor-Network Theory (ANT) as an alternative to the reductionist polarities that are present in the field of user studies. Methodology: The analysis was carried out through a bibliographic review on user studies, informational behavior, and ANT. Results: The study reveals a differentiated approach to tracking informational activities, since it considers that information users, whether individual or collective, continuously exchange properties on the same plane, without the aforementioned polarization or search for intermediate positions. Conclusions: The article presents the ART as a coherent and opportune alternative for the apprehension of contemporary informational phenomena.
\end{abstract}

RDBCl: Rev. Dig. Bibliotec e Ci. Info. / RDBCl: Dig. J. of Lib. and Info. Sci. | Campinas, SP | v.19| e021028 | 2021 


\section{Revista Digital de Biblioteconomia e Ciência da Informação D D :C Digital Journal of Library and Information Science}

KEYWORDS

Actor-network theory (ANT). Informational behavior. Information user studies.

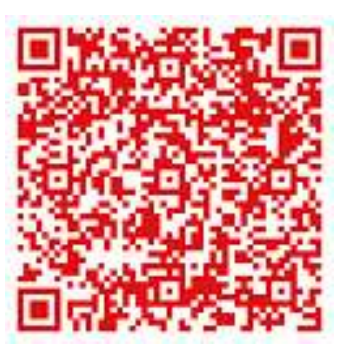

JITA: CB. User studies. 


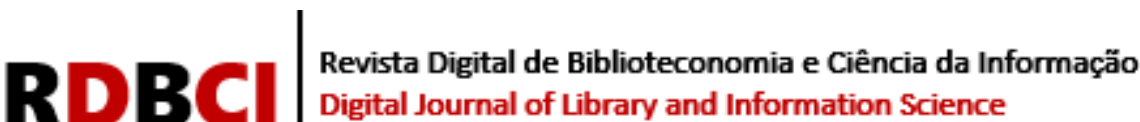

\section{INTRODUÇÃO}

O uso eficiente da informação em diferentes contextos e a identificação das necessidades e do comportamento informacional tanto dos indivíduos quanto dos grupos, ocupa lugar de destaque nas pesquisas em Ciência da Informação (CI) (MARTINEZ-SILVEIRA; ODDONE, 2007). Por isso, a abertura à observação de fenômenos informacionais por prismas distintos, não originários da $\mathrm{CI}$, potencializa novas interpretações para questões há muito sedimentadas, como as divergências entre pontos de vista distintos relativos à centralidade das atenções de pesquisa nos indivíduos, ou nos contextos. Essa polarização se deve em função de correntes de pensamentos que são menos ou mais aderentes à uma ou outra abordagem, o que permite uma interpretação de polarização entre pesquisas no campo de estudos de usuários.

Nesse sentido, esse artigo objetiva analisar a Teoria Ator-Rede (TAR) e, especialmente, alguns de seus elementos que ensejam que ela seja adotada como alternativa para o mapeamento de fenômenos informacionais, em contraponto a polaridades reducionistas presentes especialmente nos estudos de usuários da informação.

Para alcançar esse propósito, a metodologia adotada baseou-se em revisão bibliográfica que confrontou alguns aspectos dos estudos de usuários e comportamento informacional com alguns elementos fundantes do arcabouço analítico da TAR. Os achados do presente estudo indicam um caminho profícuo para investigações de fenômenos informacionais sob as lentes simétricas da TAR. Estamos diante de uma abordagem pertinente para o rastreamento de atividades informacionais por considerar que usuários da informação, sejam eles individuais ou coletivos, continuamente trocam propriedades em um mesmo plano, sem a referida polarização ou a busca por posições intermediárias.

Seguindo a estruturação do artigo, fez-se mister abstrair o que o campo de estudos de usuários tem produzido, especialmente sob alguns pontos de tensão entre correntes de pensamentos distintos. Nessa direção, a três primeiras seções se dedicam a expor, na essência, os pareceres distintos que cercam discussões ancoradas nos paradigmas desse campo. As duas seções seguintes apresentam a abordagem sociotécnica expondo os fundamentos da TAR, que preconiza uma antropologia simétrica em que os elementos que compõem as partes das redes heterogêneas são tratados sob os mesmos termos. A última sessão resgatada e confronta elementos expostos até então, propondo uma interlocução entre a TAR e os paradigmas dos estudos de usuários da informação. Por fim, são apresentadas as considerações finais e possíveis desdobramentos futuros que emergem da análise realizada.

\section{COMPORTAMENTO INFORMACIONAL: DA GÊNESE DE USUÁRIOS FOCADOS EM SISTEMAS DE INFORMAÇÃO AO COGNITIVISMO}

Desde a Conferência de Informação Científica da Sociedade Real (The Royal Society Scientific Information Conference), em 1948 no Reino Unido, os primeiros estudos na temática de usuários da informação abordaram, dentre outros temas, a coleta de dados quantitativos e a comunicação científica quando majoritariamente adotava-se questionários. Nesse primeiro momento, o foco desses estudos era o uso de informação por cientistas e engenheiros, evidenciando uma abordagem voltada para o ferramental tecnológico. Os procedimentos clássicos da biblioteconomia, como provedora de pesquisas de informações específicas aos usuários, encontram-se evidentes nesse período. A informação era percebida como objetiva e endereçava seu uso a avaliações de coleções e a sistemas de informação. Essa primeira fase, chamada "estudos de uso", é comumente referenciada como abordagem tradicional e continua 


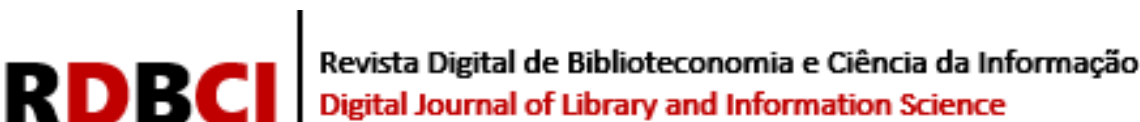

em vigor (FIGUEIREDO, 1994; ARAÚJO, 2014; ARAÚJO, 2016; SARACEVIC, 1992; COURTRIGHT, 2007; CHOO, 2006; WILSON, 2000; COSTA; GASQUE, 2010).

Embora muitos autores concordem que tenha havido uma evolução desse primeiro paradigma, de uma posição centrada no sistema para outra centrada no usuário da informação, especialmente a partir do artigo de Dervin e Nilan (1986), outros autores como Talja e Hartel (2007) argumentam que o início das pesquisas centradas no usuário remonta às décadas de 1950 e 1960

Os estudos de usuários (user studies), com o passar do tempo, passaram a ser chamados de estudos de comportamento informacional (information behavior), sugerindo um espectro mais abrangente com aspectos cognitivos (SANTOS; MARTINS, 2016). Foi Wilson (2000) que cunhou o termo comportamento informacional e propôs modelos conceituais revisitandoos mais tarde com o intuito de torná-los mais amplos em sua definição. É importante salientar que o termo comportamento informacional, segundo Gasque e Costa (2003), é majoritariamente usado na literatura internacional, enquanto no Brasil é geralmente abordado sob o rótulo de "estudos de usuários".

Em comum, os trabalhos que se debruçam sobre esse segundo momento apresentam uma perspectiva cognitivista em que se busca entender o que é a informação a partir das estruturas mentais dos usuários que se relacionam com a informação (ARAÚJO, 2009). Nesse período, alguns estudos se destacaram pela sua relevância e influência, como a teoria de sensemaking de Dervin (1998), a abordagem construtivista de Kuhlthau (1991), o estado anômalo do conhecimento de Belkin (1980), a perspectiva de valor agregado de Taylor (1986), o comportamento informacional de Wilson (1981), dentre outros. Belkin (1990) afirmou que a principal suposição do ponto de vista cognitivo é que a mente individual é a área mais importante para o processamento de informações.

Gasque e Costa (2010) esclarecem que os aspectos psicológicos, cognitivos e sociológicos ficam evidenciados nesse segundo momento, se diferenciando do aspecto positivista e behaviorista da abordagem tradicional. As autoras admitem haver avanços nessa estrutura conceitual que, dentre outras características, reconhecem a subjetividade resultante de uma realidade que não transmite significado constante. Nessa estrutura conceitual, o sistema é entendido como apenas um dos elementos de um contexto social amplo em que a individualidade e o aspecto cognitivista se tornam os principais elementos de atenção. Nesse sentido, a cerne da problemática aponta para os indivíduos e alguns aspectos ligados a eles como necessidades, motivações, hábitos e comportamentos (MATTA; SILVA, 2010).

González-Teruel (2017) fez importante contribuição ao pesquisar de forma abrangente a área de estudo de usuários nas perspectivas metodológica, epistemológica e ontológica. Sua pesquisa expôs os elementos de maior e menor vigor, no seu entendimento, ao comparar e sistematizar as publicações nos últimos anos. Seu trabalho apontou para o que chamou de paradigmas objetivista e interpretativo, presentes na tradição teórica em estudos de usuários da informação. No primeiro prevalecem o positivismo e o racionalismo, ao passo que, no segundo, predominam abordagens alternativa, construtivista e naturalista.

A necessidade de incorporar fatores sociais, culturais e históricos criou um espaço para que a atenção teórica e empírica dos pesquisadores se direcionasse para o contexto. No final dos anos 1990, o contexto havia se tornado um dos principais princípios do campo do comportamento informacional. Razão pela qual as próximas páginas são dedicadas a compreender a abordagem da centralidade baseada no contexto e sua inconsonância com a abordagem tratada no modelo cognitivo. 


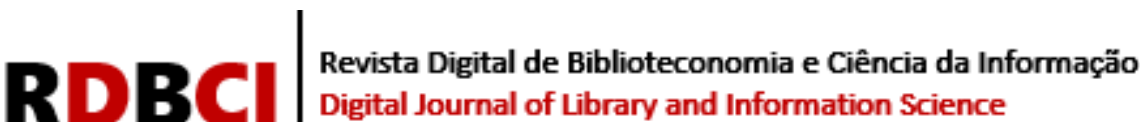

\section{A EXPANSÃO DOS ESTUDOS CENTRADOS NO CONTEXTO}

Dervin (1997, p. 14) apresenta sua interpretação de contexto como "todo atributo possível de pessoa, cultura, situação, comportamento, organização ou estrutura". Essa abordagem se distingue de abordagens de Talja, Keso e Pietiläinen (1999, p. 752), que acrescentam variáveis consideradas determinantes como "condições socioeconômicas, papéis no trabalho, tarefas, situações problemáticas, comunidades e organizações com suas estruturas e culturas etc". Já Cool, 2001 (p.8) estende sua perspectiva para uma discussão estruturada em significados e situações compostos por "ambientes dinâmicos nos quais os processos interpretativos se desdobram,". Para além dessas definições, Dervin (1997) defende que não existe um conceito de contexto que é mais usado ou mais bem definido em relação a outro.

Logo, mais importante que buscar uma definição unívoca desse conceito é entender a importância e complexidade do contexto para os estudos de usuários da informação. Além disso, entendê-lo implica reconhecer que se trata de um conjunto particular de circunstâncias a partir das quais surge uma necessidade de informação. Uma visão possível é a de que, uma vez identificada essa necessidade, "inicia-se um processo de mediação entre a informação existente recebida e o uso/aplicação da informação, para uma determinada finalidade, em um determinado contexto" (TAYLOR, 1986, p.14). Na mesma obra, o autor esboça o quanto uma informação gera percepção de valor ao usuário dependendo do contexto em que informação e ator se encontram. Assim, mensagens têm valor apenas em determinados contextos e dependem do interesse de cada usuário. $\mathrm{O}$ valor da informação pode, dessa forma, ser adicionado ou retirado de uma mensagem, fazendo que uma informação guarde uma carga potencial de interesse em função das circunstâncias em que ela se apresenta. Por outro lado, questiona-se se o indivíduo teria, de fato, capacidade para especificar exatamente uma necessidade informacional em um contexto social que se pressupõe estático e acabado (VAKKARI; SAVOLAINEN, 2003; BERTI; ARAÚJO, 2018).

$\mathrm{O}$ interesse pelo contexto fomentou a expansão dos estudos centrados no usuário e discussões teóricas e empíricas que abordam o tema. Um marco nessa evolução foi o a criação do fórum ISIC (Information Seeking in Context ${ }^{1}$ ) em 1996 que tratou de atividades de informação contextualizadas. De maneira complementar, diversos pesquisadores (WILSON, 1981; VAKKARI; SAVOLAINEN, 2003; McKENZIE, 2003; COURTRIGHT, 2007; PRESSER; SOUZA, 2012) têm se dedicado ao estudo do tema no campo do comportamento informacional. Derivam desses, dentre outros autores, uma série de abordagens que procuram explicar o comportamento informacional a partir da multiplicidade de relações com o contexto. Ou, como expõem Presser e Souza (2012), as abordagens são realizadas em diversos espaços sociais que decorrem da abertura e da dinamicidade desses contextos. Esse movimento tem ganhado força em muitas manifestações ou tentativas de representação da área. Com efeito, é oportuno considerar que, algumas delas procuram sustentar a ideia de uma ruptura do modelo cognitivista, propondo um terceiro paradigma social, de abordagem interacionista, que sugere uma independência epistemológica no campo do comportamento informacional e não uma evolução dele.

Salvo algumas exceções, o contexto como conceito aparece na literatura de pesquisa como amplamente amorfo e ilusório. Grande parte das pesquisas na área continuam equiparando o contexto a um cenário físico descritivo, onde identifica-se uma ou mais variáveis contextuais que são vistas como causais ou tangencialmente ligadas às práticas de informação

\footnotetext{
1 Posteriormente o evento mudou seu nome para The Information Behaviour Conference. Disponível em:
} http://www.isic2018.com/. Acesso em 11 out. 2021. 


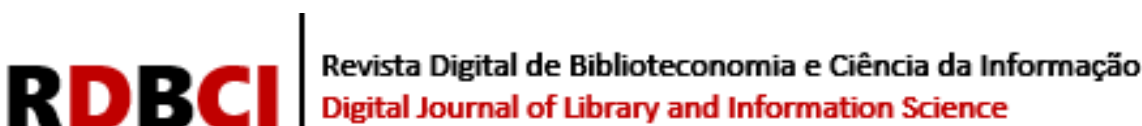

dos atores (COURTRIGHT, 2007). Por outro lado, para a autora, outras pesquisas apontam um caminho diferente: uma visão mais abrangente da complexidade do contexto e do ator nele inserido, na medida em que o posiciona incorporado a "contextos complexos, múltiplos, sobrepostos e dinâmicos, cujos elementos incluem socialidade, cultura, regras institucionais, recursos, mudança tecnológica e relações de poder, que por sua vez são moldados por atores da informação" (p. 292).

Dervin (1997, p. 112), frente a complexidade do tema, afirma que contexto tem "o potencial de ser praticamente qualquer coisa que não seja definida como o fenômeno de interesse". Por isso, propõe como alternativa epistemológica um continuum em que, de forma polarizada, encontram-se nos extremos os conceitos de "contexto como contêiner" e "contexto como portador de significado". Para o primeiro tipo, Talja, Keso e Pietiläinen (1999) esclarecem que se trata de estudos de comportamento informacional em que indivíduos ou grupos específicos são analisados tendo o contexto como pano de fundo e, por isso, chamam essa abordagem de objetiva. Para a segunda categoria, os autores consideram um deslocamento do contexto para o primeiro plano, um lugar em que o significado é socialmente construído, o que enseja que esse tipo de abordagem seja chamado de interpretativa.

\section{A DUALIDADE ENTRE INDIVÍDUO E CONTEXTO}

$\mathrm{Na}$ origem, a mudança do paradigma centrado no sistema para o centrado no usuário, como já exposto, trouxe aspectos individuais, subjetivos, situacionais e cognitivos das atividades informacionais para o primeiro plano, o que coloca ênfase no ponto de vista cognitivo. Essa perspectiva foi criticada, nas abordagens sociais emergentes, por negligenciar aspectos sociais e por tratar as atividades de informação como apartadas do contexto. Tais abordagens sociais definiram o contexto como um dos principais focos da investigação (VAKKARI; SAVOLAINEN; DERVIN, 1997; COURTRIGHT, 2007).

Esse movimento é descrito por Olsson (2004) como uma "reviravolta social" na pesquisa de comportamentos informacionais. A autora defende a ideia de que os pesquisadores considerem o contexto social como o foco fundamental de suas investigações, e não apenas como um fator que influencia os processos cognitivos individuais.

Com o passar do tempo, a dualidade de pensamentos acerca do tratamento do contexto e sua influência no campo de estudos de usuários implicou em escolhas por parte dos pesquisadores ao amparar seus respectivos pontos de vista, formando assim redutos epistemológicos.

Tabak (2014) evidencia as a dualidade dessas abordagens. Um lado do continuum é ocupado por modelos classificados do ponto de vista cognitivo, em que o conceito mais importante é a estruturação do conhecimento. Os fatores cognitivos e emocionais são vistos com pouca interferência do contexto, tendo como princípio fundamental a produção do conhecimento a partir da criação de modelos mentais. No outro extremo, as abordagens que consideram o contexto como portador de significado apresentam argumentos que refutam a posição contrária ao enfatizarem a importância do contexto sociocultural nos processos informacionais e nas interações sociais que se manifestam nos discursos e na linguagem (TALJA, 1997).

Para Tabak (2014), há abordagens intermediárias que, embora bem intencionadas, têm gerado apenas um deslocamento entre os polos opostos. Segundo ele, posicionar-se "nesse continuum se torna um ponto de diferenciação para as teorias e modelos contemporâneos de comportamento informacional, mas também uma grande dificuldade em rastrear as atividades de informação" (p. 2226). 


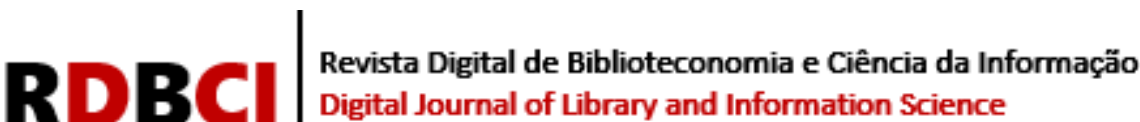

Contudo, "o caminho do meio" ou uma abordagem intermediária é proposta por autores que, num tratamento contemporâneo, consideram que as experiências são determinadas por nossa composição psicológica em que fatores culturais são mediadores da cognição. Tentativas de superação da dicotomia no campo da gestão da informação e do conhecimento podem ser apreciadas desde a teoria de contexto capacitante ou $B a$, de Nonaka e Konno (1998) ou da ecologia informacional de Davenport (1998). Mais recentemente, esforços denominados práticas informacionais, baseados em perspectivas etnometodológicas, do interacionismo simbólico e na fenomenologia, bem como nas chamadas abordagens multifacetadas (ou multidimensionais), buscam o mesmo objetivo: não negligenciar os processos cognitivos individuais. Entretanto, somam-se a eles práticas de informação com fenômenos complexos que tentam "superar a dicotomia indivíduo/social" (ARAÚJO, 2014, p.131).

Tabak (2014) esclarece que existem aqueles que argumentam que tanto o contexto quanto o indivíduo se moldam, oferecendo um compromisso entre as abordagens cognitiva e social. Nesses modelos explicativos multifacetados, segundo Pettigrew, Fidel e Bruce (2001), é preciso um esforço de integração de diversas teorias para descrevê-los. Outrossim, no decurso do tempo, tais posições dos autores podem inclusive ser alteradas, à exemplo de Brenda Dervin. Sua teoria de sense making de 1983 se modificou de um ponto de vista cognitivo, naquela década, para uma abordagem multifacetada nos anos 1990. Dervin (1997, p. 32) admite que optou por esse caminho "como uma posição apropriada para uma visão de mundo contextualista que exige atenção dialética”.

Pinto e Araújo (2019) afirmam que os discursos são construídos a partir da seleção, organização e combinação de conceitos, num contexto de disputa pelo poder e ocultamento das ideologias. Essas tensões entre os dois tipos de reducionismo, segundo Tabak (2014), são a principal dificuldade na seleção de um método para rastrear atividades de informação. Cada paradigma traz em si uma contestação sobre sua posição no continuum, mesmo antes de sua aplicação empírica, enquanto modelos antigos são modificados as vezes para ocupar uma nova posição. Nesse sentido, pode-se criar um debate interminável sobre o foco das pesquisas de comportamento informacional, limitando os estudos a um conjunto de fatores definidos a priori pelo pesquisador, tais como: cognitivo/social, objetivo/interpretativo, individual/coletivo, dentre outros. Tal circunstância, segundo o autor, paralisa a pesquisa forçando o pesquisador a lidar com os desafios de qualquer das posições escolhidas. Quando uma posição se aproxima de um polo, o risco é perder a centralidade do usuário da informação. Quando se aproxima doutro, existe o perigo de negligenciar o contexto social.

No entanto, Courtright (2007) afirma que o conceito de contexto tem um papel a desempenhar na análise do comportamento da informação. E que o paradigma centrado no usuário alcançou uma aceitação relativamente ampla entre os pesquisadores. $\mathrm{O}$ desafio das pesquisas deve ser superar as influências meramente cognitivas e afetivas, mas sem perder de vista o ator como centro das atividades informacionais. Segundo a autora, esse parece ser o caminho adequado, especialmente quando há a inserção de atores no contexto, apresentando-se como uma postura intermediária.

Portanto, posto que as tensões entre os dois tipos de reducionismo são a principal dificuldade para rastrear o comportamento dos usuários, faz-se necessário o uso de outros arcabouços teórico-metodológicos que possam dar conta das características desse campo do conhecimento e seus desafios. Por isso, faz-se mister enxergar as atividades informacionais como associações heterogêneas em que atores (ou usuários da informação) e elementos do contexto (inclusive não-humanos) agenciam uma rede contínua de interação sociotécnica. As próximas páginas irão conduzir o leitor na busca pela simetria de dualidades, presente na Teoria Ator-Rede e no hibridismo sociotécnico. 


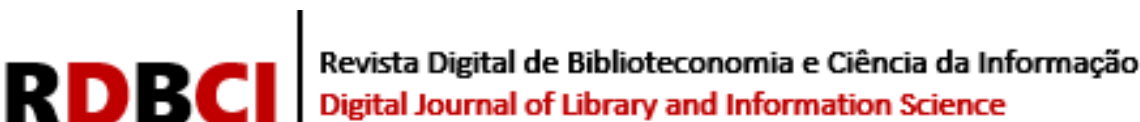

\section{AS REDES SOCIOTÉCNICAS NA CIÊNCIA DA INFORMAÇÃO}

As redes sociotécnicas são constituídas por uma aglomeração de elementos (pessoas, equipamentos, normas, técnicas, métodos, procedimentos, valores, crenças, cultura, estrutura organizacional) conectados entre si e que permanecem em constante interação para atingir um objetivo comum (VACARI, et al. 2017).

Empregar a noção de rede sociotécnica pode ajudar a superar intepretações reducionistas que consideram a existência uma relação de causalidade em uma única direção entre qualquer desses componentes. Dentre as possibilidades de abordagens sociotecnológicas, entendemos ser a TAR, proposta pelos pesquisadores Bruno Latour, John Law e Michel Callon, a mais relevante e promissora para este estudo.

$\mathrm{O}$ alcance da TAR tem se expandido significativamente desde os primeiros trabalhos publicados pelo francês Bruno Latour (ARAÚJO, 2009a; ALCADIPANI, TURETA 2009; TONELLI, 2016; CUSTÓDIO, 2018). No campo da sistemas de informação, por exemplo, as dificuldades percebidas na execução dos planos nacionais de informatização e em seus insatisfatórios resultados têm fomentado a adoção da TAR como instrumental analítico, a exemplo da pesquisa de Cavalcante et al. (2019).

Apesar de sua franca expansão, há diversas barreiras e críticas direcionadas a ela, especialmente ligadas à sua abordagem supostamente mecânica e apolítica (LEE; BROWN, 1994; WHITTLE; SPICER, 2008). Após ampla revisão da literatura, Cavalcanti e Alcadipani (2013) levantaram as quatro principais críticas à TAR: análise limitada das estruturas sociais; postura amoral ao negligenciar questões políticas e morais; atribuição de agência a nãohumanos; e possíveis problemas a respeito de como seguir as entidades numa análise das redes. Seu artigo se contrapôs a tais críticas a partir de trabalhos empíricos baseados em metodologias sugeridas por John Law, um dos principais autores a aplicar a TAR em estudos organizacionais.

Contudo, a sedimentação da TAR na CI no Brasil teve início no ano de 1995. O avanço nas investigações na área estimulou iniciativas como de Araújo (2009b), ao pesquisar trabalhos que abordassem diretamente os constructos de Bruno Latour nas bases de pesquisa em CI, o que revelou a presença de 1.235 citações em 43 artigos no período entre 1995 e 2007. O estudo identificou contribuições teórico-metodológicas da TAR ao campo, tais como a posição de "não modernidade", o conceito de informação, a construção dos fatos científicos e a proposta de "traçar um olhar simétrico na compreensão da relação homem-tecnologia" (2009b, p. 4).

Posteriormente, o estudo de Custódio (2018) cobriu o período cronológico posterior de 2007 a 2016 e evidenciou a frequência com que as ideias de Bruno Latour influenciaram temas de pesquisa nos programas de pós-graduação em CI no Brasil. Nesse recorte temporal, foi possível verificar a presença do autor em 43 citações nas 414 teses analisadas dos programas de pós-graduação que ofertam doutorado. Latour ficou na $25^{\mathrm{a}}$ posição dentre os autores internacionais mais citados, com a ocorrência de 99 citações nas teses analisadas. Acrescentase ainda que ele possui um capítulo de livro ${ }^{2}$, bem como dois artigos publicados em periódicos internacionais na área da $\mathrm{CI}^{3}$.

\footnotetext{
${ }^{2}$ LATOUR, Bruno. Redes que a razão desconhece: laboratórios, bibliotecas, coleções. In: BARATIN, Marc, JACOB, Christian (coord.). O poder das bibliotecas: a memória dos livros no ocidente. Rio de Janeiro: UFRJ, 2000b. p.21-44.

${ }^{3}$ LATOUR, Bruno; SIGOGNEAU, Maya. Une base de données bibliographiques peut-elle devenir une banque de données pour la recherche sur la recherche?. Le Documentaliste, n.4, v.5, p.139-147, 1980.
}

LATOUR, Bruno; COURTIAL, Jean-Pierre. How to measure the degree of independence of a research system? Scientometrics, Amsterdam, v.4, n.2, p. 119-33, 1981. 


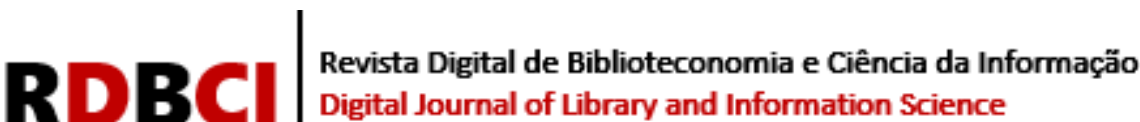

As evidências apresentadas expõem não somente as garantias literárias no campo, mas principalmente a interlocução entre a TAR e a CI. Esse entendimento nos impulsiona a apresentar na próxima sessão as contribuições que a TAR pode acrescentar ao campo dos estudos de usuários da informação.

\section{A TEORIA ATOR-REDE E A BUSCA PELA SIMETRIA}

A Teoria Ator-Rede (TAR) ou Actor Network Theory (ANT) encontra-se numa subárea denominada Science, Technology and Society (STS) que teve origem enquanto campo de pesquisa a partir da década de 1960 (LAW, 2008). Segundo Moura (2018), ela teve como influência a etnometodologia, o pós-estruturalismo, o projeto epistêmico de Michel Foucault e o conceito de rizoma proposto por Gilles Deleuze. Essa origem guarda relações com trabalhos de Micher Serres, Algirdas Greimas, Isabel Stengers, Gabriel Tarde e Harold Garfinkel (LATOUR, 2005). Embora haja, como dito, traços das ideias de Foucault na TAR, há esforços em contextualizar suas diferenças e similitudes (LAW, 1992b; BERTI; ARAÚJO, 2018). Seu uso na academia tem abarcado diversas áreas como educação, CI, psicologia, comunicação, sociologia, geografia e direito (TONELLI, 2016).

A TAR emprega um vocabulário próprio, adequado ao seu uso e com nuances e significado únicos para cada conceito. Dentre essas palavras adotadas na TAR, actante (agente ou ator) talvez seja a mais adequada como ponto de partida. Actante pode ser um humano ou não humano (como, por exemplo, processos, hardwares, softwares, documentos etc.) capaz de influenciar e alterar a rede onde está inserido. A noção de rede se apresenta como um conjunto de actantes heterogêneos conectados e agenciados. A translação (ou tradução) é entendida como um processo conduzido por actantes que resulta na construção de conexões, mobilizações, sobreposições, mediações ou interferência, e que sempre envolve transformação de um estado para outro. Controvérsias são questões ainda em aberto, sem consenso, em que os actantes discordam ou concordam na discordância, enquanto associações são conexões, vinculações entre actantes. Caixa-preta significa um elemento, fato, ou artefato da rede em estado de estagnação provisória, na medida em que cessam as controvérsias ao seu redor (LATOUR, 2011; 2012a; LAW, 1992a). Por fim, inscrições são processos de materialização de análises, como a transposição de cenários pesquisados para gráficos, tabelas, mapas que tornam os fenômenos representáveis. Essa última definição tem pontual importância na discussão seguinte, posto que, para Latour (2011), a informação é a representação que se forma entre dois lugares. O primeiro é entendido como periferia e o segundo como centro, numa conjuntura em que a inscrição circula entre eles como veículo. Esforços de ampliações, reduções e transformações são realizados para se formular as inscrições que ocorrem no que o autor chama de centro de cálculo.

Laville e Dionne (1999) alertam que os conceitos e as palavras que os exprimem são indispensáveis para conhecer, compreender e explicar. Para os autores, "conceitos são representações mentais de um conjunto de realidade em função de suas características comuns essenciais" (p. 91). Por certo, faz-se apropriado levantar uma discussão latente no campo da CI que denota uma busca pela palavra ou expressão que melhor represente o conceito de usuário da informação. Esta expressão, mais ampla e atualmente aceita no meio, tem enfrentado resistência por parte de alguns pesquisadores (DAY, 2011; RÉNDON-ROJAS;GARCÍA CERVANTES, 2012; CRUZ; ARAÚJO, 2020) por entenderem não ser suficiente para compreender as relações contemporâneos dos sujeitos com a informação. Essa discussão surge em meio à tratativa social dada aos estudos de usuários frente ao paradigma cognitivo, como já exposto. Logo, o uso do termo sujeito informacional é a proposta, por parte desses autores, para superar a inadequação ou insuficiência do termo usuário da informação. Isso não significa 


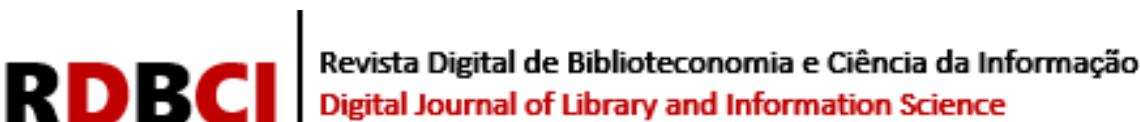

apenas a substituição do termo, mas uma mudança de perspectiva de quem se relaciona com a informação em vários contextos, formatos e espaços (CRUZ; ARAÚJO, 2020).

Contudo, sob as lentes da TAR, o usuário da informação ou sujeito informacional ganha uma dimensão distinta, dado que, por meio da informação, o agente pode intermediar contextos, espaços, outros humanos e não-humanos conectados em redes. Diante disso, e alinhado com a busca pelo termo, palavra ou conceito que melhor represente o usuário da informação, a TAR apresenta uma proposição em que o agente informacional se insere em uma posição intervencionista na informação presente na rede a que pertence. Assim, imbuindo-se do vocabulário da TAR, a palavra actante assume a posição de agente de informação que, como expõe Latour (2005), se refere a tudo que possa gerar uma ação numa rede específica e que tenha potencial para exercer alterações quando age. Na mesma obra, o autor defende sua escolha pelo termo actante dizendo que, usar a palavra ator significa que nunca é claro quem, e o que, está atuando quando agimos, dado que um ator no palco nunca estará sozinho em sua atuação. Logo, actante é um termo que expõe aquele que designa a ação. O motivo pelo qual Bruno Latour optou pelo termo actante guarda relações com o interesse em não carregar uma interpretação de subordinação entre as partes, na relação de um elemento com o outro e com o contexto. Ao ampliar o sentido de "ator" para actante, foi possível diminuir a admissão da ótica binária (sujeito-objeto).

Ademais, a TAR traz consigo o hibridismo ${ }^{4}$ sociotécnico, uma abordagem que, contrário aos pensamentos dualistas, propõe um olhar integrado, indissociável, entre o técnico e o social. Esse posicionamento traz, por consequência, opiniões diversas sobre o uso da TAR. Entretanto, são exatamente essas opiniões diversas que contribuem para emergência de paradigmas e enriquecem as discussões epistemológicas (SERVA;DIAS; ALPERSTEDT, 2010) até então ignoradas, ou com potencial para confrontos ou interlocuções. É nesse sentido que o presente artigo se propõe a abordar o dilema dos dualismos no campo de estudos de usuários da informação.

Os fundamentos da TAR evocam mudanças radicais na forma de representação da natureza e da sociedade, ao atacar conceitos tradicionais como "os dualismos metafísicos da cultura ocidental" (BOLZANI JUNIOR, 2017, p. 89). Ao refutar oposições binárias, a teoria de Bruno Latour propõe uma nova dinâmica onde o social versus o indivíduo, a agência versus a estrutura, as escolhas versus a ordem, são deslocados para uma análise simétrica que não privilegia a autonomia das partes, mas permite uma nova constituição delas através de suas interações (DELANDA, 2010).

Essas interações ocorrem entre as entidades ${ }^{5}$, que só passam a existir em função, ou por meio, de um conjunto de relações. Trata-se de uma interpretação da semiótica chamada por Law (1999) de semiótica da materialidade. Dessa forma, uma entidade somente a será em função dos elementos com quem ela se relaciona permanecerem (LAW, 2002). Sendo assim, a TAR assume que a existência dos atores não precede a existência das redes em que eles se inserem, trazendo um viés de percepção, por exemplo, diferente da habitual corrente de análise organizacional (DAVENPORT, 2006). Logo, a TAR busca repelir as polarizações parametrizando humanos e não humanos sem que haja neles assimetrias. Nessa direção, não se considera que elementos naturais e tecnológicos tenham uma fronteira bem delimitada. Por isso, ambos devem ser tratados de maneira integrada e por meio do mesmo vocabulário de análise (LAW, 1987).

\footnotetext{
${ }^{4} \mathrm{O}$ termo híbrido já não é mais utilizado por Latour (2004), que afirma que necessariamente só há híbridos, em toda parte. $\mathrm{O}$ termo matters of concern passa a substituir a expressão original em suas obras recentes.

${ }^{5} \mathrm{O}$ termo entidade é entendido na TAR como um elemento não passível de identificação, podendo ser ele portanto, humano ou não-humano.
} 


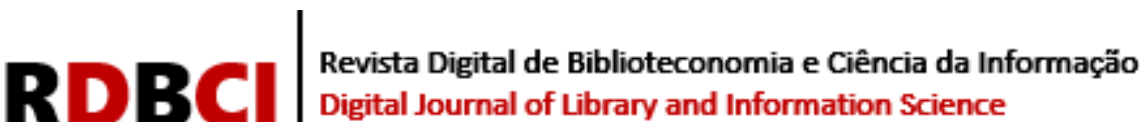

\section{RESULTADOS E DISCUSSÃO: TAR COMO ALTERNATIVA SIMÉTRICA ÀS DUALIDADES DO COMPORTAMENTO INFORMACIONAL}

Uma vez adotada uma centralidade no usuário, ou no contexto, ou a possibilidade de posicionamentos intermediários ao longo do continuum, tem-se assim perspectivas não aderentes ao olhar da TAR, uma vez que nela não há esse tipo de arbitragem. Para a TAR, tratase apenas da circulação contínua de processos de individualização e coletivização, na qual cognitivo e social, humano e não humano, usuário e contexto trocam constantemente propriedades. Por conseguinte, nessa perspectiva, um contexto nunca é um contêiner para os usuários, mas um efeito da própria contextualização dos usuários (TABAK, 2014). Essa condição permite ignorar as divisões entre indivíduos e coletivos, porque a TAR é uma configuração híbrida, que é simultaneamente um ponto (ou um indivíduo) e uma rede (ou coletivo) (CALLON; LAW, 1997). Essa distinção não é apenas desnecessária, mas equivocada, já que a fonte da ação não está no "contexto social" ou no "indivíduo conhecedor", mas é um efeito do arranjo de materiais heterogêneos. Trata-se de um efeito da circulação na qual o indivíduo e o coletivo transmudam constantemente propriedades (TABAK, 2014), o que significa que a ação não pode ser explicada "de maneira reducionista, como uma consequência firme de qualquer ação anterior específica" (CALLON; LAW, 1997, p. 179).

Logo, individual e coletivo, num ciclo, já não são mais os mesmos quando comparados num ciclo posterior. Em outras palavras, Latour (2012) mostra que a individualização estabiliza um indivíduo, como a coletivização estabiliza um coletivo, mas apenas por um breve momento, de modo que esse indivíduo/coletivo estabilizado é apenas um ponto de partida para outro indivíduo/coletivo em outro ciclo. No entanto, seria equivocado afirmar que esses fatores são simultaneamente individuais e coletivos, pois não são simultaneamente, mas sim sequencialmente, fabricantes e manufaturados. De maneira análoga, o olhar da TAR ignora dicotomias pois cada "parte é tão grande quanto o todo, que é tão pequena quanto qualquer outra parte" (LATOUR; HERMANT, 1998, p. 45)

A TAR, portanto, oferece uma abordagem diferenciada que considera que informações e usuários, individuais ou coletivos, continuamente trocam propriedades, sem colocar o foco nos indivíduos e (ou) no contexto. Assim, a posição provisória de um sujeito informacional, proposto aqui como actante, pode desencadear, conforme seus interesses e translações, uma reação do coletivo que compõem essa mesma rede. Nessa condição, existe a possibilidade, em uma rede, de controvérsias se estabilizarem por associações, fundindo-se numa caixa preta de materiais heterogêneos em que o coletivo, mais uma vez, torna-se individualizado.

Por conseguinte, acompanhar os actantes que estabilizam uma rede sociotécnica de interesses razoavelmente instáveis permite rastrear fenômenos informacionais com possibilidades de entender as associações e controvérsias até então invisíveis, que podem interferir no comportamento informacional de um usuário da informação. Assumir que a informação se manifesta e translada sem o locus confinante do "indivíduo" ou do "contexto" pode revelar forças sociais e (ou) cognitivas por trás das atividades informacionais. Os possíveis resultados advindos dessa abordagem se tornariam imperceptíveis pelas lentes de pesquisas convencionais em estudos de usuários, seja pela pouca flexibilidade dos posicionamentos dualistas quando comparada às lentes da TAR, seja pela baixa fluidez de estados que cada entidade se encontra frente a sua relação temporária com as demais entidades que compõem a mesma rede sociotécnica.

Assim, a TAR reivindica para si posições de simetria que permitem analisar o contexto e as decisões nele tomadas sem que qualquer das partes, como por exemplo, usuários (humanos) e sistemas (não-humanos), sejam diminuídas em sua essência e importância. Esses coletivos 


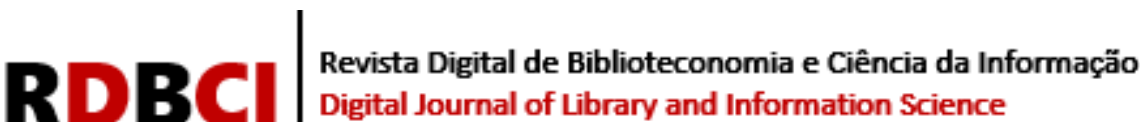

híbridos, na opinião de Latour (2012a), são uma "purificação" do conhecimento, na medida em que a sociologia do conhecimento critica os binarismos ao negar a existência de uma fronteira entre dualidades. $\mathrm{O}$ autor apresenta uma perspectiva em que não existem objetos e sujeitos puros, uma vez que os objetos são subjetivantes e os sujeitos são objetivantes, portanto híbridos.

Logo, um caminho alternativo, em contraposição a esse tipo de encarceramento dualístico, mostra-se não apenas coerente, mas oportuno ao repertório metodológico de rastreio de fenômenos informacionais no campo de estudos de usuários, notadamente do comportamento informacional. Essa possibilidade faculta, de maneira complementar, uma nova perspectiva, ou uma releitura sobre pesquisas já concluídas no campo, ao possibilitar eventuais confrontos de resultados sobre diferentes pontos de vista.

\section{CONCLUSÃO}

A Teoria Ator-Rede pode ser entendida como uma reunião de distintas possibilidades de modelos analíticos, a tal ponto que Law (2007) defende a ideia de que não existe apenas uma TAR. Ela vai além de velhas categorias estruturalistas e fornece ferramentas analíticas para a compreensão de objetos fluidos e mutantes (CAVALCANTI; ALCADIPANE, 2013), o que estimulou os autores desse artigo a confrontá-la com os estudos de comportamento informacional.

Embora, como já explicitado, existam esforços de superação da dicotomia em estudos de usuários da informação, a TAR oferece um olhar distinto, uma rota alternativa sustentada na promessa simétrica da neutralidade, ainda que sobre o mesmo intuito: solucionar as polaridades presentes no campo. Objetivou-se assim apresentar a TAR e, especialmente, alguns de seus elementos que ensejam que ela seja adotada como alternativa para o mapeamento de fenômenos informacionais, em contraponto a polaridades reducionistas presentes especialmente nos estudos de usuários da informação. Para Tonelli (2016, p. 388), esforços dessa natureza são relevantes, "uma vez que se percebe um crescente interesse da comunidade acadêmica por orientações teóricas que fogem ao mainstream funcionalista".

A proposta teórico-metodológica da TAR foi apresentada como uma alternativa à superação das dualidades presentes em algumas abordagens dos estudos de comportamento informacional. Esta proposta mostra-se com considerável potencial, especialmente no rastreio de fenômenos informacionais complexos e instáveis que não poderiam ser solvidos simplesmente pelo determinismo humanista ou pelo determinismo tecnológico, bem como pelo paradigma cognitivo ou social. Destarte, para superar a dualidade de interpretações que opõem humanos e não humanos, social e técnico, contexto e indivíduo, abordagem alternativa e interacionista, objetivo e interpretativo, paradigma cognitivo e social, a abordagem teóricometodológica da TAR toma como unidade de análise as tessituras sociotécnicas heterogêneas chamadas de híbridas por Latour (2012a).

O movimento de escolha de alguma posição no continuum, antes mesmo da investigação empírica de um fenômeno, interfere na abordagem que o pesquisador aplicará em sua pesquisa. Essa escolha afeta os futuros achados em função do ponto de vista defendido pelo pesquisador. Logo, não se trata pura e simplesmente de uma crítica ao dualismo centrado no contexto ou no indivíduo, mas fundamentalmente ao cárcere que conduz pesquisas e pesquisadores a resultados alinhados a uma escolha que antecede os resultados. Uma escolha que, invariavelmente, confirma e (ou) refuta pressupostos epistemológicos de um ou outro polo dos estudos de comportamentos informacionais. Transpor o olhar, muitas vezes dualístico ou polarizado, para as lentes simétricas da TAR permite ao investigador uma projeção diferente em que, por exemplo, sistemas de informação, deixam de ser recursos ou contextos numa perspectiva de contêiner. Para a TAR, sistemas de informação, tanto quanto qualquer outro 


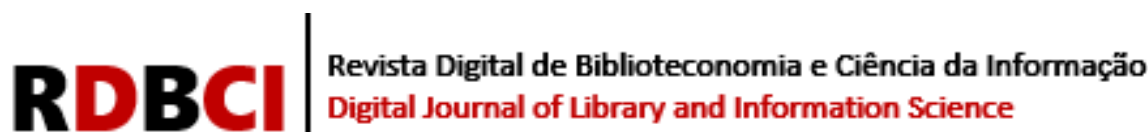

elemento, são atores ou redes, realocados em um mesmo plano sem privilégios. Tal simetria generalizada na TAR, traz a ideia de uma ferramenta heurística adequada para entender o papel contingencial exercido pelos actantes dentro da rede da qual fazem parte.

Como desdobramentos futuros às discussões apresentadas, estimula-se a condução de pesquisas que possam tratar o rastreamento de fenômenos informacionais de forma empírica, utilizando a TAR como orientação teórica e metodológica em contraponto a rotulação pertencente ao quadro cognitivo ou social. Esse estímulo é compartilhado com Cavalcanti e Alcadipani (2013), que afirmam que John Law deixou como legado uma base metodológica que acolhe a complexidade e possibilita alcançar uma variedade expressiva de análises processuais de informações em abordagens empíricas.

\section{CRediT}

RECONHECIMENTOS: Não aplicável.

FINANCIAMENTO: Não é aplicável.

CONFLITOS DE INTERESSE: Os autores certificam que não têm interesse comercial ou associativo que represente um conflito de interesses em relação ao manuscrito.

APROVAÇÃO ÉTICA: Não é aplicável.

DISPONIBILIDADE DE DADOS E MATERIAL: Não é aplicável.

CONTRIBUIÇÕES DOS AUTORES: Conceituação, Metodologia, Administração do projeto, Supervisão, Escrita revisão \& edição: ANDRADE, E. A.; MARQUES, R. M.; Curadoria de dados, Investigação, Visualização, Escritarascunho original Investigação: ANDRADE, E. A.

\section{REFERÊNCIAS}

ALCADIPANI, Rafael.; TURETA, Cesar. Teoria ator-rede e estudos críticos em administração: possibilidades de um diálogo. Cadernos EBAPE.BR, v.7, n. 3, p. 405-418, set. 2009. Disponível em: https://www.scielo.br/scielo.php?script=sci arttext\&pid=S167939512009000300003. Acesso em: 21 set. 2019

ARAÚJO, Carlos Alberto Ávila. Correntes teóricas da ciência da informação. Ciência da Informação, Brasília, DF, v. 38, n. 3, p. 192-204, set./dez., 2009. Disponível em: https://www.scielo.br/pdf/ci/v38n3/v38n3a13. Acesso em: 15 nov. 2020

ARAÚJO, Carlos Alberto Ávila. Arquivologia, biblioteconomia, museologia e ciência da informação: o diálogo possível. Brasília: Briquet de Lemos, 2014. 196 p. Disponível em: https://periodicos.unb.br/index.php/museologia/article/view/17180. Acesso em: 10 out. 2020

ARAÚJO, Carlos Alberto Ávila. Estudos de usuários da informação: comparação entre estudos de uso, de comportamento e de práticas a partir de uma pesquisa empírica.

Informação em Pauta, Fortaleza, v. 1, p. 61-78, 30 jun. 2016. Disponível em: http://www.periodicos.ufc.br/informacaoempauta/article/view/2970. Acesso em: 25 jul.2019

ARAUJO, Ronaldo Ferreira de. Apropriações de Bruno Latour pela Ciência da Informação no Brasil: descrição, explicação e interpretação. Perspectivas em Ciência da Informação, Belo Horizonte, v. 14, p. 240-240, 2009a. Disponível em: 


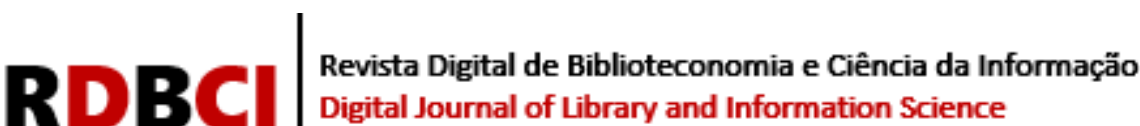

https://www.scielo.br/scielo.php?pid=S1413-99362009000300021\&script $=$ sci arttext. Acesso em: 17 set 2020

ARAUJO, Ronaldo Ferreira de. Leituras de Bruno Latour na ciência da informação: analisando citações. Ponto de Acesso, Salvador, v. 3, p. 299-316, 2009b. Disponível em: https://www.researchgate.net/publication/330299229 LEITURAS DE BRUNO LATOUR NA CIENCIA DA INFORMACAO ANALISANDO CITACOES. Acesso em: 01 mai 2020

BELKIN, Nicholas J. Anomalous states of knowledge as a Basis for Information Retrieval. The Canadian Journal of Information Science, v. 5, p. 133-143, 1980. Disponível em: https://tefkos.comminfo.rutgers.edu/Courses/612/Articles/BelkinAnomolous.pdf. Acesso em: 08 jan 2021

BELKIN, Nicholas J. The cognitive viewpoint in information science. Journal of Information Science, v. 16, n. 1, p. 11-15, 1990. Disponível em: https://journals.sagepub.com/doi/abs/10.1177/016555159001600104. Acesso em: 24 nov 2020

BERTI, Ilemar Christina Lansoni Wey; ARAÚJO, Carlos Alberto Ávila. Pressupostos da teoria ator-rede para os estudos das práticas informacionais. Informação \& SociedadeEstudos, v. 28, n. 2, p. 285-294, 2018. Disponível em: https://periodicos.ufpb.br/index.php/ies/article/view/38024. Acesso em: 03 dez. 2020

BOLZANI JÚNIOR, Geraldo Morceli. Avaliação em estudos de futuros de setores industriais na perspectiva da teoria ator-rede. Estudo de caso: Observatórios da Indústria do Sistema Federação da Indústria do Estado do Paraná (FIEP). 2017. Tese (Doutorado em Tecnologia e Sociedade) - Universidade Tecnológica Federal do Paraná, Curitiba. Disponível em: http://repositorio.utfpr.edu.br/jspui/handle/1/2555. Acesso em: 15 nov. 2020

CALLON, Michael; LAW, John. After the individual in society: Lessons on collectivity from science, technology and society. The Canadian Journal of Sociology / Cahiers canadiens de sociologie, v. 22, n. 2, p. 165-182. 1997. Disponível em https://www.brown.edu/Departments/Joukowsky_Institute/events/cogutmaterialworlds/files/5 586882.pdf. Acesso em: 17 nov. 2020

CAVALCANTE, Ricardo Bezerra; ESTEVES, Cristiano José da Silva; GONTIJO, Tarcísio Laerte; BRITO, Maria José Menezes; GUIMARAES, Eliete Albano de Azevedo. Rede de atores e suas influências na informatização da Atenção Básica à Saúde no Brasil. Interface, v. 23, 2019.

CAVALCANTI, Maria Fernanda Rios; ALCADIPANI, Rafael. Organizações como processos e Teoria Ator Rede: a contribuição de John Law. Cadernos EBAPE.BR, v. 11, n. 4, p. 556568, 2013. Disponível em: https://www.scielo.br/scielo.php?pid=S167939512013000400006\&script $=$ sci abstract\&tlng=pt. Acesso em: 08 dez. 2020

CHOO, Chun Wei. A organização do conhecimento: como as organizações usam a informação para criar significado, construir conhecimento e tomar decisões. São Paulo: Senac, 2006. 


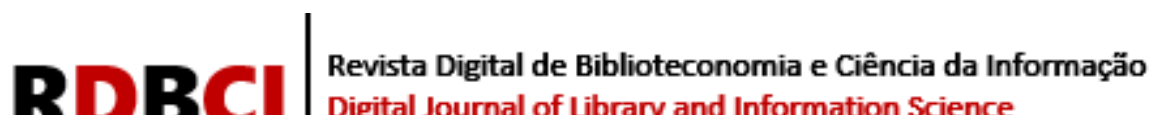 \\ Digital Journal of Library and Information Science}

COOL, Colleen. The concept of situation in information science. Annual Review of Information Science and Technology, v. 35, p. 5-42. 2001. Disponível em: https://eric.ed.gov/?id=EJ639574. Acesso em: 08 jan. 2021

COURTRIGHT, Christina. Context in information behavior research. Annual Review of Information Science and Technology, v. 41, n. 1, p. 273-306. 2007. Disponível em: https://asistdl.onlinelibrary.wiley.com/doi/10.1002/aris.2007.1440410113. Acesso em: 19 nov. 2020

CRUZ, Ruleanderson do Carmo; ARAÚJO, Carlos Alberto Ávila. Sujeito informacional, conceito em emergência: uma revisão teórico-conceitual de periódicos Ibero-Americanos. Informação \& Sociedade-Estudos, v. 30, p. 1-22, 2020. Disponível em: https://periodicos.ufpb.br/ojs2/index.php/ies/article/view/43934. Acesso em: 07 fev. 2021

CUSTÓDIO, Pollyana Ágata Gomes da Rocha. As bases teóricas expressas nas teses dos programas de pós-graduação em Ciência da Informação no Brasil: uma análise cientométrica. 2018. Tese (Doutorado em Ciência da Informação) - Faculdade de Filosofia e Ciências, Universidade Estadual Paulista, Marília. Disponível em:

https://repositorio.unesp.br/handle/11449/154015. Acesso em: 19 nov. 2020

DAVENPORT, Elisabeth. Actor-network theory and organizing. Management Learning, v. 37, n. 2, p. 248-250, 2006. Disponível em:

https://journals.sagepub.com/doi/10.1177/135050760603700208. Acesso em: 25 jan. 2021

DAY, Ronald E. Death of the user: reconceptualizing subjects, objects, and their relations.

Journal of the American Society for Information Science and Technology, Silver Spring, v. 62, n. 1, p. 78-88, 2011. Disponível em:

http://onlinelibrary.wiley.com/doi/10.1002/asi.21422/epdf. Acesso em: 08 fev. 2021.

DELANDA, Manuel. Deleuze: History and Science. New York: Atropos Press, 2010.

DERVIN, Brenda; NILAN, Michael. Information needs and uses. Annual Review of Information Science and Technology, v. 21, p. 3-33. 1986. Disponível em: http://www2.hawaii.edu/ donnab/lis670/dervin_nilan.pdf. Acesso em: 08 out. 2020

DERVIN, Brenda. Given a context by any other name: Methodological tools for taming the unruly beast. In: VAKKARI Pertti.; SAVOLAINEN Reijo; DERVIN Brenda (ed.)., Information seeking in context. London: Taylor Graham. 1997. p. 13-38. Disponível em: http://tefkos.comminfo.rutgers.edu/Courses/612/Articles/dervin97context.pdf. Acesso em: 10 out. 2020

DERVIN, Brenda. Sense-making theory and practice: an overview of user interests in knowledge seeking and use. Journal of Knowledge Management, v. 2, n. 2, dec. 1998. Disponível em:

https://www.emerald.com/insight/content/doi/10.1108/13673279810249369/full/html. Acesso em: 10 out. 2020

FIGUEIREDO, Nice Menezes de. Estudos de uso e usuários da informação. Brasília: IBICT, 1994. Disponível em: http:/livroaberto.ibict.br/handle/1/452. Acesso em: 04 fev 2021 


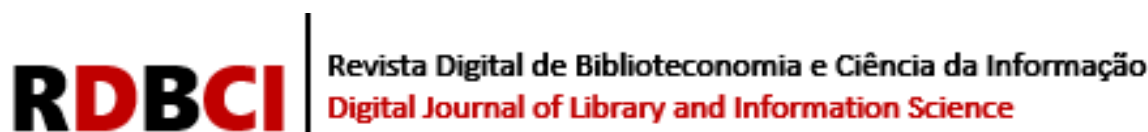

GASQUE, Kelley Cristine Gonçalves Dias; COSTA, Sely Maria de Souza. Comportamento dos professores da educação básica na busca da informação para formação continuada.

Ciência da Informação, v. 32, n. 3, p. 54-61, set./dez. 2003. Disponível em: https://www.scielo.br/scielo.php?pid=S0100$19652003000300007 \&$ script=sci_abstract\&tlng=pt. Acesso em: 16 fev. 2021

GASQUE, Kelley Cristine Gonçalves Dias; COSTA, Sely Maria de Souza. Evolução teóricometodológica dos estudos de comportamento informacional de usuários. Ciência da Informação, v. 39, n. 1, p. 21-32, jan./abr., 2010. Disponível em: https://www.scielo.br/pdf/ci/v39n1/v39n1a02. Acesso em: 08 jan. 2021

GONZÁLEZ-TERUEL, Aurora. Referentes teóricos y dimensiones aplicadas en el studio del usuario de la información. In: GONZÁLEZ-DE-GÓMEZ, M. Nélida; RABELLO, Rodrigo (ed.). Informação: agentes e intermediação. Brasília: Instituto Brasileiro de Informação em Ciência e Tecnologia, 2017. p, 135-194. Disponível em: http://eprints.rclis.org/31733/. Acesso em: 09 fev. 2021

KARI, Jarkko; SAVOLAINEN, Reijo. Towards a contextual model of information seeking on the Web. New review of information behaviour research, v, 4, n. 1, p. 155-175, 2003. Disponível em: https://www.tandfonline.com/doi/abs/10.1080/14716310310001631507. Acesso em: 13 dez. 2020

KUHLTHAU, Carol C. Inside the search process: information seeking from the users perspective. Journal of the American Society for Information Science, Washington, 1991, v. 42, n. 5, p. 361-371. Disponível em: https://ils.unc.edu/courses/2014_fall/inls151_003/Readings/Kuhlthau_Inside_Search_Process 1991.pdf. Acesso em: 15 nov. 2020

LATOUR, Bruno. Reassembling the social: An introduction to actornetwork- theory. Oxford, UK: Oxford University Press, 2005. Disponível em: https://is.muni.cz/el/fss/jaro2017/SAN103/um/Latour_Reassembling the_Social.pdf. Acesso em: 05 fev. 2021

LATOUR, Bruno. Ciência em ação: como seguir cientistas e engenheiros sociedade afora. 2.ed. São Paulo: Editora UNESP, 2011. 422 p. Disponível em: https://www.scielo.br/scielo.php?script=sci arttext\&pid=S1414-32832000000100014. Acesso em: 03 dez 2019

LATOUR, Bruno. Reagregando o social: uma introdução à teoria do ator-rede.

Salvador/Bauru: Edufba/Edusc, 2012a. Disponível em: https://periodicos.ufsc.br/index.php/ilha/article/view/2175-8034.2012v14n1-2p238. Acesso em: 05 fev. 2020

LATOUR, Bruno. Faturas/Fraturas: da noção de rede à noção de vínculo. ILHA, v. 16, n. 2, p. 123-146. 2015. DOI http://dx.doi.org/10.5007/2175-8034. Disponível em: https://periodicos.ufsc.br/index.php/ilha/issue/view/3120. Acesso em: 17 dez. 2020. 


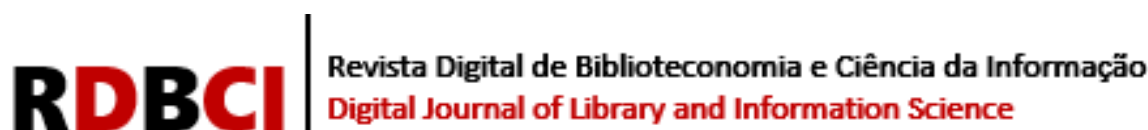

LATOUR, Bruno; HERMANT, Emilie. Paris: Invisible city. Paris: La Découverte-Les Empêcheurs de penser en rond, 1998. Disponível em : http://www.brunolatour.fr/virtual/PARIS-INVISIBLE-GB.pdf. Acesso em : 12 dez. 2020

LAVILLE, Christian; DIONNE, Jean. A construção do saber: manual de metodologia de pesquisa em ciências humanas. Belo Horizonte: UFMG, 1999. Disponível em:

https://edisciplinas.usp.br/pluginfile.php $/ 287028 / \mathrm{mod}$ resource/content $/ 1 /$ Laville $\% 2 \mathrm{C} \% 20 \mathrm{Ch}$ ristian $\% 20 \% 20$ Dionne $\% 2$ C $\% 20$ Jean_A $\% 20$ Construcao $\% 20$ do $\% 20$ Saber $\% 20 \% 28$ completo $\%$ 29.pdf. Acesso em: 19 out 2020

LAW, John. The structure of sociotechnical engineering: a review of the new sociology of technology. The Sociological Review, v. 35, n. 2, p. 404-425, 1987. DOI: $\underline{10.1111 / \mathrm{j} .1467-}$ 954X.1987.tb00015.x. Disponível em:

https://www.researchgate.net/publication/229707066 The Structure_of_Sociotechnical_Engi neering - A Review of the New Sociology of Technology. Acesso em: 08 jan. 2021

LAW, John. Notas sobre a teoria do ator-rede: ordenamento, estratégia e heterogeneidade. Tradução: Fernando Manso. 1992a. Disponível em:

http://www.necso.ufrj.br/Trads/Notas\%20sobre\%20a\%20teoria\%20Ator-Rede.htm. Acesso em: 02 mar. 2020

LAW, John. Where are the missing masses? The sociology of a few mundane artifacts. In: BIJKER, Wiebe.; LAW, John (ed.). Shaping technology/building society: studies in sociotechnical Change. London: MIT Press, 1992b. Disponível em: http://www.brunolatour.fr/sites/default/files/50-MISSING-MASSES-GB.pdf. Acesso em: 05 out. 2020

LAW, John. After ANT: complexity, naming and topology. In: LAW, John.; HASSARD, John. (ed.). ANT and After. Oxford, Blackwell/Sociological Review. p.1-14, 1999. DOI: https://doi.org/10.1111/j.1467-954X.1999.tb03479.x. Disponpivel em:

https://journals.sagepub.com/doi/10.1111/j.1467-954X.1999.tb03479.x. Acesso em: 05 jan 2021

LAW, John. Objects and spaces. Theory, culture \& society, [S.l.], v.19, n. 5/6, 2002. Disponível em: http://ewasteschools.pbworks.com/f/Law2002ObjectsandSpacesTheoryCulture\%26Society.pd f. Acesso em: 05 dez. 2020

LAW, John. On sociology and STS. The sociological review. v. 56, n. 4, p. 623-649, 2008. DOI: https://doi.org/10.1111/j.1467-954X.2008.00808.x. Disponível em: https://journals.sagepub.com/doi/10.1111/j.1467-954X.2008.00808.x. Acesso em: 17 dez. 2020

LEE, N.; BROWN, S. Otherness and the Actor Network - the undiscovered Continent. American Behavioral Scientist, v. 37, n. 6, p. 772-790, 1994

MARTINEZ-SILVEIRA, Martha Silvia; ODDONE, Nanci. Necessidades e comportamento informacional: conceituação e modelos. Ciência da Informação, Brasília, v. 36, n. 1, p. 118127, maio/ago. 2007. DOI: 10.1590/S0100-19652007000200012. Disponível em: 


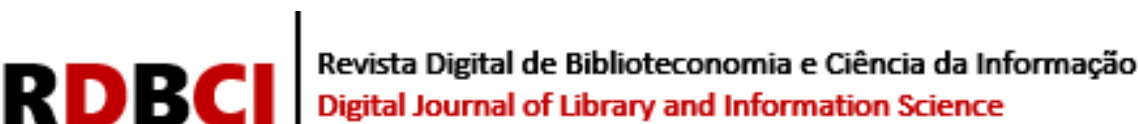

https://www.scielo.br/scielo.php?script=sci_arttext\&pid=S010019652007000200012\&lng=pt\&tlng=pt. Acesso em: 03 fev.2021

MATTA, Rodrigo Octávio Beton; SILVA, Helen de Castro. Em busca de um modelo de comportamento informacional de usuários de informação financeira pessoal. In: ENCONTRO NACIONAL DE PESQUISA EM CIÊNCIA DA INFORMAÇÃO, ANCIB, 11., 2010.

Anais... [S.l.], 2010. p. 1-21. Disponível em:

http://repositorios.questoesemrede.uff.br/repositorios/bitstream/handle/123456789/1713/Em\% 20busca\%20-\%20Matta.pdf?sequence=1. Acesso em: 28 jan. 2021

MCKENZIE, Pamela J. A model of information practices in accounts of everyday-life information seeking. Journal of Documentation, v. 59, n. 1, p. 19-40, 2003. Disponível em: https://citeseerx.ist.psu.edu/viewdoc/download?doi=10.1.1.464.2799\&rep=rep1\&type=pdf. Acesso em: 15 fev. 2021

MOURA, Carolina Silva de. Associações sociotécnicas: Mediações algorítmicas e a economia das ações no Facebook. 2018. Dissertação (Mestrado em Comunicação) - Programa de Pós-graduação em Comunicação - Universidade Federal de Goiás -Goiânia. Disponível em: https://repositorio.bc.ufg.br/tede/handle/tede/8427. Acesso em: 04 abr. 2020

NONAKA, Ikujiro; KONNO, Noboru. The Concept of "Ba": Building a foundation for knowledge creation. California Management Review, v 3, n. 40, spring, 1998. Disponível em: https://home.business.utah.edu/actme/7410/Nonaka\%201998.pdf. Acesso em: 01 mar. 2021

OLSSON, Michael. Understanding users: Context communication and construction. Challenging ideas: ALIA 2004 Biennial Conference (p. 1-9). Gold Coast, Australia: Australian Library and Information Association, 2004.

PETTIGREW, Karen E.; FIDEL, Raya; BRUCE Harry. Conceptual frameworks in information behavior. Annual Review of Information and Technology. v. 35 p. 43-78, 2001. Disponivel em:

http://faculty.washington.edu/fidelr/RayaPubs/ConceptualFrameworks.pdf. Acesso em: 20 out. 2020

PINTO, Flávia Virginia Melo; ARAÚJO, Carlos Alberto Ávila. Estudos de usuários: quais as diferenças entre os conceitos comportamento informacional e práticas informacionais?

Ciência da Informação em Revista, Maceió. v. 6, n. 3, p. 15-33, set./dez, 2019. Disponível em: https://www.seer.ufal.br/index.php/cir/article/view/8037. Acesso em: 18 dez. 2020

PRESSER, Nadi Helena; SOUZA, Edivanio Duarte. Comportamento informacional em ambientes organizacionais: abordagem de estudo do contexto social. In: ENCONTRO NACIONAL DE PESQUISA EM CIÊNCIA DA INFORMAÇÃO - ENANCIB, 13., Rio de Janeiro, 2012. Anais... 2012. Rio de Janeiro, 2012. Disponível em: https://bit.ly/3HI7xxn. Acesso em: 12 jan. 2021

RENDÓN-ROJAS, Miguel Ángel; GARCÍA CERVANTES, Alejandro Luis. El sujeto informacional en el contexto contemporáneo. Un análisis desde la epistemología de la identidad comunitariainformacional. Encontros Bibli: revista eletrônica de biblioteconomia e 


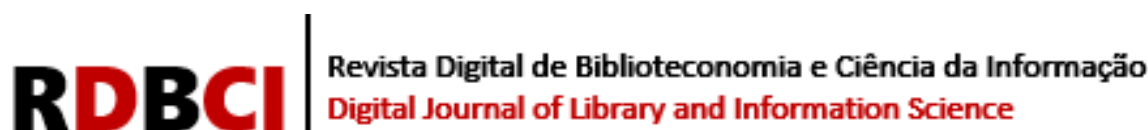

ciência da informação, Florianópolis, v. 17, n. 33, p. 30-45, jan./abr. 2012. Disponível em: https://ur.booksc.org/dl/73549412/f6cdc0?jsh=ab295759482755c6. Acesso em: 03 fev. 2021

SANTOS, Fernando Bittencourt dos; MARTINS, Maria Fernanda da Silva. Comportamento informacional de profissionais da área de meteorologia do Brasil e de Portugal: um estudo exploratório. Páginas a\&b. v. 3 (especial), p. 73-86, 2016. Disponível em: http://ojs.letras.up.pt/index.php/paginasaeb/article/view/1452. Acesso em: 19 dez. 2020

SARACEVIC, Tefko. Information Science: origins, evolution lations. In: VAKKARI, Pertti., CRONIN, Blaise (ed.). Conceptions of library and information science. Graham Taylor, London and Los Angeles, p. 5-27, 1992. Disponível em:

https://www.academia.edu/925298/Information science origin evolution and relations. Acesso em: 04 set. 2020

SERVA, Maurício; DIAS, Taisa; ALPERSTEDT Graziela Dias. Paradigma da complexidade e teoria das organizações: uma reflexão epistemológica. Revista de Administração de Empresas, v. 50, n. 3, p. 276-287, 2010. Disponível em: https://www.scielo.br/pdf/rae/v50n3/04.pdf. Acesso em: 01 out. 2020

TABAK, Edin. Jumping between context and users: A difficulty in tracing information practices. Journal of the Association for Information Science and Technology, v. 65, n. 11, p. 2223-2232, 2014. Disponível em:

https://asistdl.onlinelibrary.wiley.com/doi/abs/10.1002/asi.23116. Acesso em: 24 abr. 2020

TALJA, Sanna. Constituting "information" and "user" as research objects: A theory of knowledge formations as an alternative to the information man-theory. In: VAKKARI, Pertti; SAVOLAINEN, Reijo; DERVIN Brenda. (ed.). Proceedings of an International

Conference on Information Seeking in Context. London: Taylor Graham Publishing, 1997, p. 67-80. Disponível em: https://tefkos.comminfo.rutgers.edu/Courses/612/Articles/Talja.pdf. Acesso em: 02 mai. 2020

TALJA, Sanna.; KESO, Heidi; PIETILÄINEN, Tarja. The production of "context" in information seeking research: A metatheoretical view. Information Processing \& Management, v. 35, n. 6, p. 751-763, 1999. Disponível em: https://www.sciencedirect.com/science/article/abs/pii/S0306457399000242. Acesso em: 15 nov. 2020

TALJA, Sana; HARTEL, Jenna. Revisiting the user-centered turn in information science research: An intellectual history perspective. Information Research, v. 12, n. 4, 2007. Disponível em: http://informationr.net/ir/12-4/colis04.html. Acesso em: 15 nov. 2020

TAYLOR, Robert S. Value-added processes in information systems. Norwood: Ablex, 1986. DOI: https://doi.org/10.1002/leap/10034br3. Disponível em: https://onlinelibrary.wiley.com/doi/abs/10.1002/leap/10034br3. Acesso em: 22 fev. 2020

TONELLI, Dany Flávio. Origens e afiliações epistemológicas da Teoria Ator-Rede: implicações para a análise organizacional. Cadernos EBAPE.BR. v. 14, n. 2, p. 377-390, 2016. DOI: https://doi.org/10.1590/1679-395141596. Disponível em: 


\section{RDBCI|}

https://www.scielo.br/scielo.php?pid=S1679-

39512016000200377\&script=sci abstract\&tlng=pt. Acesso em: 20 fev. 2021

VACARI, Isaque et al. Desenvolvimento de Software na Embrapa: Abordagem a partir da Teoria Ator-Rede. Revista Brasileira de Gestão e Inovação, v. 4, n. 3, p. 64-88, 2017.

Disponível em: http://www.ucs.br/etc/revistas/index.php/RBGl/article/view/4925. Acesso em: 15 nov. 2020

VAKKARI, Pertti.; SAVOLAINEN, Reijo; DERVIN, Brenda. (ed.). Information seeking in context: proceedings of an international conference on research in information needs, seeking and use in different contexts. London: Taylor Graham, 1997. Disponível em: http://www.gbv.de/dms/goettingen/236936123.pdf. Acesso em: 17 dez. 2020

WILSON, Thomas Daniel. On user studies and information needs. Journal of Documentation, London. v.37, n. 1, p. 3-15, 1981. Disponível em:

https://www.researchgate.net/publication/249364883 On_User_Studies_and_Information_Ne eds. Acesso em: 15 jan. 2021

WILSON, Thomas Daniel. Human information behavior. Informing Science Research, v.3, n.2, p. 49-55, 2000. Disponível em: http://inform.nu/Articles/Vol3/v3n2p49-56.pdf. Acesso em: 12 dez. 2020. 


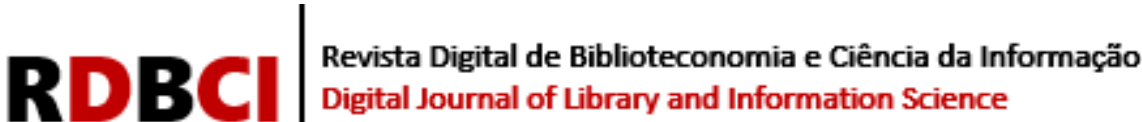

